This is a self-archived version of an original article. This version may differ from the original in pagination and typographic details.

Author(s): Rantalainen, Timo; Finni, Taija; Walker, Simon

Title: Jump Height from Inertial Recordings : A Tutorial for a Sports Scientist

Year: 2020

Version: Accepted version (Final draft)

Copyright: ㄷ 2019 John Wiley \& Sons A/S

Rights: In Copyright

Rights url: http://rightsstatements.org/page/lnC/1.0/?language=en

Please cite the original version:

Rantalainen, T., Finni, T., \& Walker, S. (2020). Jump Height from Inertial Recordings : A Tutorial for a Sports Scientist. Scandinavian Journal of Medicine and Science in Sports, 30(1), 38-45.

https://doi.org/10.1111/sms.13546 
DR TIMO RANTALAINEN (Orcid ID : 0000-0001-6977-4782)

PROFESSOR TAIJA FINNI (Orcid ID : 0000-0002-7697-2813)

DR SIMON WALKER (Orcid ID : 0000-0002-6804-0741)

Article type : Original Article

\section{Jump Height from Inertial Recordings; a Tutorial for a Sports Scientist}

Timo Rantalainen ${ }^{1}$, Taija Finni ${ }^{1}$, Simon Walker ${ }^{1}$

${ }^{1}$ Faculty of Sport and Health Sciences, Neuromuscular Research Center, University of Jyväskylä, Jyväskylä, Finland.

\section{Running head: IMU-based jump height}

\section{Address for Correspondence:}

Dr Timo Rantalainen

Gerontology Research Center

Faculty of Sport and Health Sciences

University of Jyväskylä

P.O. Box 35 (viv 249)

This article has been accepted for publication and undergone full peer review but has not been through the copyediting, typesetting, pagination and proofreading process, which may lead to differences between this version and the Version of Record. Please cite this article as doi: $10.1111 / \mathrm{sms} .13546$

This article is protected by copyright. All rights reserved. 
40014 University of Jyvaskyla

Finland

Email: timo.rantalainen@jyu.fi; Tel. +358 40805 3252; Fax +358 142601021

\section{Abstract}

Jump performance provides meaningful information both for sporting and clinical needs. Current state-of-the-art in jump performance assessment is laboratory-bound, however, outof-the-laboratory methods are desirable. Therefore, the purposes of the present investigation were 1) to explore whether utilising a novel analytical approach minimises the bias between inertial recording unit (IMU)-based and jump mat-based jump height estimates, and 2) to provide a thorough tutorial for a sport scientist (see appendix) to facilitate standardisation of jump height estimation.

Forty one women, men and boys aged 6 to 77 years-of-age completed three maximal counter movement jumps without arm swing, which were concurrently registered with a jump mat, and an IMU worn in low lumbar region.

Excellent agreement between the novel IMU-based jump height and jump mat jump height was observed (mean IMU 22.6 [8.3] cm, mean jump mat 22.7 [8.9], mean bias $-0.1 \mathrm{~cm}$ [95\% limits of agreement $-4.5 \mathrm{~cm}$ to $4.4 \mathrm{~cm} ; \mathrm{p}=0.826]$, intra-class correlation coefficient 0.97 [95\% CI 0.94 to $0.98, \mathrm{p}<0.001])$. 
In conclusion, inertial recordings conducted with lightweight IMUs worn on the hip provide a valid and feasible assessment of jump height among people with varying athletic ability. Inertial signals have the potential to afford (at least semi-) automated analysis pipeline with low labour cost thus being potentially feasible in applied settings such as in professional sports or in the clinics.

Keywords: inertial measurement unit; wearable; performance; signal processing; accelerometer; gyroscope;

\section{Introduction}

Jumping performance is thought to reflect lower body power production capacity, and counter movement jump performance is widely utilised as an indicator of athletic ability among athletes ${ }^{1-3}$, in monitoring recovery from injury ${ }^{4,5}$, and as an indicator of functional ability among older individuals ${ }^{6}$. Jump performance is typically assessed using laboratory equipment, such as a force plate ${ }^{7,8}$ or a $3 \mathrm{D}$ motion capture system ${ }^{8,9}$, which can produce valid and reliable estimates of jump height. However, there are occasions in which jump height, and jump volume estimates would be desirable to be obtained in a field setting. For example, jumping is an integral part of many team sports, such as volleyball ${ }^{10}$, and while appropriate amounts of jumping optimise bone health ${ }^{11}$ excessive jumping volume is thought to underpin common overuse injuries such as tendinopathy ${ }^{10}$. Moreover, being able to measure out of the laboratory enables assessing individuals in their habitual environment and enables 
participation to those who would be burdened by a trip to the laboratory (e.g. children, athletes recovering from injury, elderly people). Therefore, a need exists for reliable portable equipment to evaluate jump performance in the out-of-the-laboratory-setting.

Portable methods for jump assessments found from the literature include a jump-and-reach device $^{9,12}$, a jump mat ${ }^{13-15}$, video camera (based on flight time measured from the take-off frame to the touchdown frame ${ }^{16}$ ), and wearable sensors ${ }^{8,15,17-20}$. Commercially available wearable sensors, inertial measurement units (IMU) in particular, have received recent interest. An IMU comprises an accelerometer and a gyroscope and many sensors also include a magnetometer (magneto-inertial measurement unit). IMUs are extremely portable and affordable, as well as being able to be used in various testing environments. As opposed to the other portable options, IMUs do not need to be used on a pre-specified measurement site, and are therefore able to be used even during game play (e.g. football [soccer] ${ }^{21}$ and Australian Rules Football ${ }^{22}$ have allowed IMUs during official matches). However, the numerical processing required to estimate jump height based on inertial recordings is not entirely trivial to implement. In fact, anecdotally, although wearable devices incorporating inertial sensors are currently being worn in official games for load-monitoring purposes, at least in the Australian Football League, the inertial recordings are more or less ignored partially due to the difficulty in extracting valuable information from the recorded signals. Even when the recordings from the inertial sensors are leveraged, proprietary commercial approaches are often used for jump detection and jump height estimation ${ }^{12,23,24}$. This practice is less than ideal in the scientific context and may limit the usage due to the added costs for users with less economic advantages compared to free and open approaches. Moreover, jump height can be obtained from inertial recordings with multiple approaches, e.g. based on the 
flight-time and on the take-off velocity ${ }^{8,15,17,25}$. Therefore a fully transparent, standardised approach to jump height estimation based on inertial recordings would arguably be desirable.

Once vertical acceleration has been obtained from the sensor with the aid of an orientation correction (which requires at the minimum 3D accelerations and rotations ${ }^{26}$, please see further details under the Methods section), at least three methods could be utilised to evaluate jump height. That is, jump height could be estimated based on; 1) flight time $e^{8,15,17,25}$,2) takeoff velocity ${ }^{8,15,17}$, or 3 ) concentric net impulse ${ }^{27}$ (the full derivation of the three methods mentioned is given in the supplementary digital content SDC 1). The flight-time-based approaches are susceptible to changes in posture between the take-off and the landing instants (e.g. tucking the knees while in air would inflate the flight time), whereas such in-flight kinematics have no effect on the take-off velocity or concentric net impulse. Nevertheless, we have found flight-time-based approaches to produce better concurrent validity and reliability compared to take-off velocity-based (and by extension impulse-based as both rely on similar numerical techniques) approaches ${ }^{8,15}$, and therefore only flight-time based approaches are considered below. Flight time could be evaluated based on the vertical acceleration using at least two methods. That is, one could extract; a) the timings of take-off and touchdown acceleration trace directly to estimate flight time (by utilising a threshold above free fall, akin to how one might do with a force $\operatorname{trace}^{28}$ ), or one could b) integrate the acceleration signal, and derive the flight time as the difference between the highest (occurs just prior to take-off) and the lowest velocity (occurs just after touchdown) recorded throughout the jump ${ }^{8,15}$. In practice the best congruence between wearable inertial sensor-based jump height and jump height evaluated with force plates or motion capture have been reported based on flight time defined using the method ' $b$ ' described above ${ }^{8,15,17}$. However, it is well-established that the velocity extrema-based timings (method ' $b$ ') will produce an overestimate of the flight time 
due to the extrema occurring prior to take off (maximum velocity) and after touchdown (minimum velocity) ${ }^{8,15,17-20}$. Due to the noise caused by the movement of the sensor relative to the body during take-off and landing ${ }^{8,29}$, it is challenging to utilise the acceleration tracebased flight-time method (method 'a'), and this approach remains scarcely explored in the literature. Due to the one-to-one proportionality between acceleration and force, one might expect a smaller bias against a contact mat with this method compared to the velocityextrema method for determining flight time.

The purposes of the present paper and associated materials are two-fold; 1) to explore whether a novel method utilising the acceleration trace to refine flight-time estimate (method 'a') might minimise the bias between IMU-based and jump mat-based jump height estimates, and 2) to provide a thorough, transparent tutorial (https://cmj.sport.jyu.fi/) for a sport scientist on the signal processing required to estimate jump height based on inertial recording to facilitate the process of standardisation of jump height estimation based on inertial recordings. All analysis implementation and video tutorials detailing the analysis are included in the online materials.

This article is protected by copyright. All rights reserved. 


\section{Materials and Methods}

A convenience sample of $N=41$ individuals aged 6 to 77 years-of-age were sampled in the 2018 European Researchers' Night event at the University of Jyväskylä, Finland campus. The exclusion criteria included being unable to safely complete maximal counter movement jumps, or the inability to consent. Inclusion criteria included ability to consent, willingness to take part, and ability to complete the testing safely. In accordance with the local legislation the University of Jyväskylä Ethical Committee provided a letter stating that the study did not require ethical review due to the fully anonymous data collection, and the non-medical and non-invasive study design. The study was conducted in agreement with the Helsinki Declaration. Either an informed written or verbal consent (under-aged participants; $\mathrm{N}=3$ ) was obtained from all participants, with written informed consent obtained from the guardians of the under-aged participants.

\subsection{Protocol}

The participants self-reported their age, height, weight and sex, and were asked to wear an elastic belt with a magneto-inertial measurement unit (3-dimensional accelerations $\pm 16 \mathrm{~g}$, rotations $\pm 2000 \%$ and magnetic field $\pm 1300 \mu \mathrm{T}$ recorded at $400 \mathrm{~Hz}, 400 \mathrm{~Hz}$ and $20 \mathrm{~Hz}$ sample rates, respectively, NGIMU, x-io Technologies Limited, UK) positioned on the back mid-line at the L3 to L5 level. The participants were then instructed on the required counter movement jumping technique verbally and the experimenter also demonstrated the technique with a sub-maximal jump. The participants were instructed to complete a counter movement jump with their hands on their hip throughout the jump to minimise upper body contribution 
on the performance. They were also instructed to avoid excessive upper body movement by maintaining their gaze on the horizon and asked to jump as high as possible for maximal performance. Two to four practice jumps were then completed followed by maximal effort testing. A short period of rest in the order of $30 \mathrm{~s}$ was allowed between jumps, and maximal effort trials were repeated until the two best jumps produced results within $5 \%$ of each other. This resulted in three to six maximal efforts being conducted (we only recorded the two last jumps for one participant, and did not record practice jumps for another participant; online materials). The jumps were conducted on a custom-made jump mat, which recorded flight time to the nearest $1 / 1000^{\text {th }}$ of a second.

\subsection{Numerical analysis}

All numerical analysis with the data used for calculations, as well as videos explaining the analysis step-by-step are provided at https://cmj.sport.jyu.fi/. Brief scientific description is provided below.

Accelerations were calculated in the global coordinate system by applying a java implementation of Madgwick's gradient descent orientation estimate ${ }^{26}$ algorithm (Matlab implementation by Madgwick http://x-io.co.uk/open-source-imu-and-ahrs-algorithms, a java implementation is included in the online materials). Only accelerometer and gyroscope signals were utilised in producing the orientation estimate in the present study. Accelerations and rotations are sufficient to calculate the global vertical acceleration, and including the magnetometer readings are thus unnecessary. However, in the absence of the magnetometer data the directions of the horizontal accelerations in the global coordinate system remain 
undetermined (Figure 1). The algorithm returns the quaternion conjugate of the orientation quaternion needed to rotate the accelerations from the sensor coordinate system to a global coordinate system where the third axis points up along the vertical axis. Therefore, the quaternion conjugate was taken from the returned orientation quaternion, and, thereafter, the sensor accelerations were multiplied with the conjugated orientation quaternion using equation;

$$
\bar{a}_{\text {global }}=q * \bar{a}_{\text {sensor }} * q^{-1}(1)
$$

, where a horizontal line on top of a symbol indicates a vector, $\mathrm{a}=$ acceleration, $\mathrm{q}=$ orientation quaternion, and * indicates a quaternion product. The sensor accelerations were prefixed with a zero (i.e. $[\mathrm{x}, \mathrm{y}, \mathrm{z}]$ becomes $[0, \mathrm{x}, \mathrm{y}, \mathrm{z}]$ ) to turn the acceleration vector into a quaternion for the quaternion product, and the first element was subsequently discarded from the global accelerations vector. Only the global vertical acceleration was considered in further calculations.

Velocity was calculated from the vertical acceleration by trapezoidal integration. Subsequently, a $0.1 \mathrm{~Hz}$ high-pass $4^{\text {th }}$ order zero-lag Butterworth filter was applied to minimise integration drift. In order to detect the jumps the vertical acceleration was then filtered with a digital $2 \mathrm{~Hz}$ low-pass $4^{\text {th }}$ order zero-lag Butterworth filter, and continuous epochs of $\geq 0.15 \mathrm{~s}$ below $0.5 \mathrm{~g}$ were identified from the filtered acceleration as potential jump epochs. The $0.5 \mathrm{~g}$ threshold was determined experimentally with lower thresholds consistently (erroneously) identifying one of the oscillations of the accelerometer due to the whipping at take-off and landing, thus shortening the flight time. The potential jumps were 
explored by extending the potential jump epoch by $1 \mathrm{~s}$ to either direction and identifying the maximum and the minimum velocity from this extended epoch.

The instant of maximal velocity was defined as the take-off instant, and the instant of the minimal velocity was defined as the touchdown instant. The flight epoch was defined as the epoch from the take-off to the touchdown. Subsequently the potential jumps were pruned by requiring that the mean raw (i.e. not filtered) vertical acceleration was less than $0.5 \mathrm{~g}$ during flight, flight time was between 0.2 to $0.9 \mathrm{~s}$, and only the first jump of any overlapping jump epochs was retained. This procedure resulted in a manageable number of jumps to manually sort into actual jumps and false positives. The included flight time interval corresponds to jump heights from $4.9 \mathrm{~cm}$ to $99.3 \mathrm{~cm}$ and was determined based on anecdotal experience. The highest recorded jump height in our laboratory with the protocol utilised in the present study is approximately $75 \mathrm{~cm}$. It is worth noting that jumps utilising a run-up and an arm swing may exceed the $99.3 \mathrm{~cm}$ jump height. In healthy older adults, it is also unusual to record jump heights of $<5 \mathrm{~cm}$, and so this was deemed a suitable cut-off. Users may wish to tailor these limits to suit their own population of interest. In addition to defining the flight time as described above (corresponding to method ' $b$ ' from the introduction), flight time was also determined by refining the take-off and touchdown instants based on the raw vertical acceleration signal (corresponding to method 'a' from the introduction). The refinement of the take-off instant was done by considering the epoch from $-0.1 \mathrm{~s}$ to $0.04 \mathrm{~s}$ surrounding the take-off instant based on the procedure described above and defining take-off as the first instant, which had acceleration less than $0.5 \mathrm{~g}$. Touchdown instant was refined by considering the $-0.1 \mathrm{~s}$ to 0.1 surrounding the touchdown instant based on the procedure described above, and defining the touchdown instant as the last instant, which had acceleration less than $0.5 \mathrm{~g}$.

This article is protected by copyright. All rights reserved. 
Jump height for flight times defined with both the method ' $a$ ' and the ' $b$ ' was calculated as (the formulation of the equation given in the supplementary digital content SDC 1);

$$
\text { jump height }=\frac{g}{8} * \text { flight time } e^{2}
$$

, where $g=9.81 \mathrm{~m} / \mathrm{s}^{2}$ and the resulting jump height is given in $\mathrm{m}$. The same equation was also used to derive the jump height from the jump mat-measured flight time.

\subsection{Statistical analysis}

Mean (SD) are reported where applicable. The required sample size was determined based on analysis by Glüer et al. ${ }^{30}$, which showed that $\mathrm{N}=27$ with two repeated measures provides reasonable confidence intervals for assessments of repeatability and due to the statistical evaluation being similar for validity. We included all data recorded and thus the study had adequate statistical power. The validity of the IMU-derived jump height (both method ' $a$ ' and 'b') was evaluated against the concurrent jump mat-derived jump height with mean difference (bias, evaluated with paired t-tests), 95\% limits of agreement (95\% LoA), Pearson correlation coefficient, and intra-class correlation coefficient (calculated for consistency ${ }^{31}$, ICC. Method was used as the 'rater', and the mean of the method as the 'ranking'. i.e. $\left.\mathrm{ICC}_{3,1}\right)$. ICCs were used to describe the correspondence as poor $(<0.40)$, fair $(0.40$ to $<0.60)$, good $(0.60$ to $<0.75)$ or excellent $(\geq 0.75)^{32}$. Statistical significance for the difference between methods was evaluated with a paired t-test. Bland Altman plots ${ }^{33}$ are presented to 
visually display the mean difference and range of difference (mean bias and 95\% LoA) between the measurement techniques. Kendall's Tau $(\tau)$ between the mean and the norm of the difference between methods was used to explore whether heteroscedasticity was present and $\tau<0.1$ was considered not heteroscedastic ${ }^{34}$. Statistical analysis was run on Matlab (version 9.1.0.441655, R2016B, MathWorks Inc., USA) and statistical significance was set at $\mathrm{p} \leq 0.05$

\section{Results}

A total of 41 women $(\mathrm{N}=25)$, men $(\mathrm{N}=13)$ and boys $(\mathrm{N}=3)$ from 6 to 77 years-of-age took part in the study. Descriptive characteristics are given in Table 1. The mean jump height based on the jump mat was $22.7(8.9) \mathrm{cm}$ and $22.6(8.3) \mathrm{cm}$ based on the inertial measurement unit using method 'a'. Method ' $b$ ' resulted in mean jump height of 26.7 (7.9) $\mathrm{cm}$. Methods ' $a$ ' and ' $b$ ' produced strongly associated results $(r=0.97, p<0.001$; Figure 2$)$.

No significant bias was observed between jump mat and method 'a' $-0.1 \mathrm{~cm}(95 \%$ LoA -4.5 to $4.4 ; \mathrm{p}=0.826$ ), whereas the mean bias between the jump mat and method ' $\mathrm{b}$ ' was $3.9 \mathrm{~cm}$ (95\% LoA -2.3 to $10.2 \mathrm{~cm} ; \mathrm{p}<0.001)$. Neither method exhibited heteroscedasticity $(\tau=-0.02$ and -0.10 for method ' $a$ ' and ' $b$ ', respectively). Method 'a' produced excellent congruence against jump mat between jump height estimates with an ICC of 0.97 (95\% confidence interval 0.94 to $0.98, \mathrm{p}<0.001$ ) (Figure 3). The corresponding result for method ' $\mathrm{b}$ ' also exhibited excellent congruence (ICC $=0.9395 \%$ CI 0.87 to $0.96, p<0.001$, Figure 4 ).

This article is protected by copyright. All rights reserved. 


\section{Discussion}

The primary finding of the study was that the methods presented to estimate jump height based on inertial recordings had excellent congruence to jump mat-derived jump heights. The novel analysis method of refining IMU-determined flight time based on the vertical acceleration trace characteristics (method 'a') led to no statistically significant bias between the jump mat and the IMU-assessed jump heights. However, in line with what has been reported by us ${ }^{8,15}$ and by others ${ }^{17-20}$, significant mean bias with respect to jump mat-assessed jump height was observed between the methods when velocity extrema were used to determine the flight time to derive jump height (method ' $b$ '). Moreover, the limits of agreement were slightly narrower using method ' $a$ ' compared to method ' $b$ '. Therefore, the refinement of the flight time using the acceleration signal characteristics seemed to be justified and might be preferable over method ' $b$ ', despite the latter being simpler to implement.

The present findings are well in-line with previous explorations of the validity of IMUderived jump height when evaluated against a jump mat, force plate or motion capture in various populations. That is ICCs ranging from 0.83 to 0.98 have been reported in the literature ${ }^{8,15,17-20}$. Two novel additions to the numerical analysis of the accelerometry signal were presented in the present paper in that; 1) integration drift was eliminated from the integrated velocity with a high-pass filter, and 2) flight time was refined based on the acceleration (method ' $a$ '). The former would obviously render the absolute velocity value invalid, but the treatment seemed feasible for extracting the timings of the extrema as required to determine flight time based on the velocity. The latter seemed a rather successful 
modification to the main body of literature, and resulted in an ICC at the top end of the range reported in the literature ${ }^{8,15,17-20}$. Based on the good correspondence and minimal bias compared to a jump mat we suggest that the method 'a' presented in the present paper should be considered as a potential standard approach to be adopted for IMU-based jump height estimation.

We have previously shown that IMU-derived jump height based on flight time is repeatable from day-to-day ${ }^{8}$, and concurrent validity was observed in the present study as well as in numerous other studies ${ }^{8,15,17-20}$. Taken together, these results indicate that IMUs could be used to evaluate athletic performance, monitor athletic performance prospectively. If the approach was validated for a particular sport (e.g. the effect on reliability of utilising arm swing, which is invariably a part of sport-specific jumping) it could also be used in evaluating the jumping load of an exercise bout. This would be of particular utility in sports such as volleyball where the jumping is specifically suspected to underpin the aetiology of overuse injury $^{10}$, where labour-intensive video analysis present the de facto current state of the $\operatorname{art}^{12,35}$. This sort of individualised load monitoring based on wearable GPS monitors worn by each member of the team is already current practice in some outdoor sports ${ }^{21,22}$, and could be extended to indoor sports with wearable IMUs. The open source materials with the implementation of the analysis of the present study are meant to; 1) facilitate the adoption and uptake of IMU-technology amongst sports scientists who might not have the time or interest to implement the required numerical analyses, and 2) help standardise the numerical approach used to evaluate jump height based on inertial recordings.

This article is protected by copyright. All rights reserved. 
This study had some limitations that need to be considered when interpreting the findings. Maximal positive and negative velocity were used as the take-off and touchdown instants in defining flight time. This will lead to an overestimate of the flight time because maximal velocity occurs prior to the actual take-off, and minimal velocity occurs after the actual touchdown. These instants were used because there is no other conspicuous characteristic of acceleration or velocity that can be used to define the actual take-off and touchdown instants.

On the other hand when we refined the flight time based on the accelerometry signal (method 'a') we had to carefully fine-tune the parameters (epoch considered for adjustments) for the present dataset. Even though the refinement led to results that were closer to the jump mat results, this requires more human oversight compared to simply relying on the velocity extrema. Whether or not suitable parameters can be obtained for a particular population remains to be explored but, until such time, method 'a' may require more laborious human involvement compared to method 'b' presented in the present paper. That is, the velocity extrema were consistently identified correctly and could potentially have been used without human assessment, whereas the identification of the acceleration crossing the $0.5 \mathrm{~g}$ threshold required human inspection. As such, even though it is apparently less precise, method ' $b$ ' may be more feasible for continual load monitoring applications. Finally, jump mat is not considered a 'gold standard' method for jump performance evaluation. However, jump mats have been shown to exhibit excellent external validity against force plates ${ }^{13,14}$ and thus we decided to use a jump mat as a reasonable reference due to practical reasons.

In conclusion, inertial recordings conducted with highly portable IMUs provide a valid, reliable and feasible assessment of jump height among people with varying athletic ability. While other portable solutions for the purpose exist, IMUs have the benefit of being wearable, and can thus be used to monitor a bout of loading, including training/competition. 
Moreover, inertial signals are of the kind that afford (at least semi-) automated analysis pipeline with low labour cost thus enabling widespread use in applied settings such as in professional sports or in the clinics.

\section{Perspectives}

The miniaturisation of inertial sensors, minimisation of energy demands, and increased data storage capacity has enabled the use of wearable inertial sensors in training load monitoring over prolonged periods of time. Moreover, the measurement range, and resolution of wearable sensors have improved to such an extent as to enable detailed performance evaluation. Anecdotally, sports scientists are not necessarily well equipped with this flood of time series data, and tend to default to proprietary black box software for numerical analyses. The aim of the present manuscript was two-fold 1) to help standardise wearable sensor-based jump height assessment, and 2) to help sports scientists familiarise themselves with the steps required to implement analyses starting from the recorded signals. The former helps with improving the comparability between studies while the latter is a prerequisite for the development of analytical approaches to wrangle the mass of time series data flooding in from wearable sensors used in load monitoring among athletes, and regular people alike.

This article is protected by copyright. All rights reserved. 


\section{Conflict of interest statement}

Declarations of interest: none.

\section{Acknowledgements}

Tutorial videos are hosted by the University of Jyväskylä, Finland, and are available at https://cmj.sport.jyu.fi/.

\section{References}

1. Bosco C, Komi PV. Mechanical characteristics and fiber composition of human leg extensor muscles. Eur J Appl Physiol 1979;41:275-284.

2. Coburn JW. Measuring Power. Strength Cond J 2012;34:25-28.

3. McMaster DT, Gill N, Cronin J, McGuigan M. A Brief Review of Strength and Ballistic Assessment Methodologies in Sport. Sports Med 2014;44:603-623.

4. Souissi S, Wong DP, Dellal A, Croisier JL, Ellouze Z, Chamari K. Improving functional performance and muscle power 4-to- 6 months after anterior cruciate ligament reconstruction. J Sports Sci Med 2011;10:655.

5. Holsgaard-Larsen A, Jensen C, Mortensen NHM, Aagaard P. Concurrent assessments of lower limb loading patterns, mechanical muscle strength and functional performance in ACL-patients - A cross-sectional study. The Knee 2014;21:66-73.

6. Siglinsky E, Krueger D, Ward RE, Caserotti P, Strotmeyer ES, Harris TB, Binkley N, Buehring B. Effect of age and sex on jumping mechanography and other measures of muscle mass and function. J Musculoskelet Neuronal Interact 2015;15:301-308.

7. Bosco C, Luhtanen P, Komi PV. A simple method for measurement of mechanical power in jumping. Eur J Appl Physiol 1983;50:273-282.

This article is protected by copyright. All rights reserved. 
8. Rantalainen T, Gastin PB, Spangler R, Wundersitz D. Concurrent validity and reliability of torso-worn inertial measurement unit for jump power and height estimation. J Sports Sci 2018;36:1937-1942.

9. Leard JS, Cirillo MA, Katsnelson E, Kimiatek DA, Miller TW, Trebincevic K, Garbalosa JC. Validity of two alternative systems for measuring vertical jump height. J Strength Cond Res 2007;21:1296-1299.

10. Van der Worp H, de Poel H, Diercks R, van den Akker-Scheek I, Zwerver J. Jumper's Knee or Lander's Knee? A Systematic Review of the Relation between Jump Biomechanics and Patellar Tendinopathy. Int J Sports Med 2014;35:714-722.

11. Sievänen H. Bone: Impact loading — nature's way to strengthen bone. Nat Rev Endocrinol 2012;8:391-393.

12. MacDonald K, Bahr R, Baltich J, Whittaker JL, Meeuwisse WH. Validation of an inertial measurement unit for the measurement of jump count and height. Phys Ther Sport 2017;25:15-19.

13. Glatthorn JF, Gouge S, Nussbaumer S, Stauffacher S, Impellizzeri FM, Maffiuletti NA. Validity and reliability of Optojump photoelectric cells for estimating vertical jump height. J Strength Cond Res 2011;25:556-560.

14. Rogan S, Radlinger L, Imhasly C, Kneubuehler A, Hilfiker R. Validity Study of a Jump Mat Compared to the Reference Standard Force Plate. Asian J Sports Med 2015;6:.

15. Rantalainen T, Hesketh KD, Rodda C, Duckham RL. Validity of hip-worn inertial measurement unit compared to jump mat for jump height measurement in adolescents. Scand J Med Sci Sports 2018;28:2183-2188.

16. Yingling VR, Castro DA, Duong JT, Malpartida FJ, Usher JR, O J. The reliability of vertical jump tests between the Vertec and My Jump phone application. PeerJ 2018;6:e4669.

17. Casartelli N, Müller R, Maffiuletti NA. Validity and reliability of the Myotest accelerometric system for the assessment of vertical jump height. J Strength Cond Res 2010;24:3186-3193.

18. Picerno P, Camomilla V, Capranica L. Countermovement jump performance assessment using a wearable 3D inertial measurement unit. J Sports Sci 2011;29:139-146.

19. Castagna C, Ganzetti M, Ditroilo M, Giovannelli M, Rocchetti A, Manzi V. Concurrent validity of vertical jump performance assessment systems. J Strength Cond Res 2013;27:761-768.

20. Lesinski M, Muehlbauer T, Granacher U. Concurrent validity of the Gyko inertial sensor system for the assessment of vertical jump height in female sub-elite youth soccer players. BMC Sports Sci Med Rehabil 2016;8:35.

21. Buchheit M, Hammond K, Bourdon PC, Simpson BM, Garvican-Lewis LA, Schmidt WF, Gore CJ, Aughey RJ. Relative Match Intensities at High Altitude in HighlyTrained Young Soccer Players (ISA3600). J Sports Sci Med 2015;14:98-102.

This article is protected by copyright. All rights reserved. 
22. Young WB, Hepner J, Robbins DW. Movement Demands in Australian Rules Football as Indicators of Muscle Damage. J Strength Cond Res 2012;26:492-496.

23. Charlton PC, Kenneally-Dabrowski C, Sheppard J, Spratford W. A simple method for quantifying jump loads in volleyball athletes. J Sci Med Sport 2017;20:241-245.

24. Spangler R, Rantalainen T, Gastin PB, Wundersitz D. Inertial Sensors are a Valid Tool to Detect and Consistently Quantify Jumping. Int J Sports Med 2018;39:802-808.

25. Requena B, García I, Requena F, Saez-Saez de Villarreal E, Pääsuke M. Reliability and Validity of a Wireless Microelectromechanicals Based System $\left(\right.$ Keimove $\left.^{\mathrm{TM}}\right)$ for Measuring Vertical Jumping Performance. J Sports Sci Med 2012;11:115-122.

26. Madgwick SOH, Harrison AJL, Vaidyanathan R. 2011. Estimation of IMU and MARG orientation using a gradient descent algorithm. In: 2011 IEEE International Conference on Rehabilitation Robotics (ICORR).1-7.

27. Rantalainen T, Nikander R, Heinonen A, Multanen J, Häkkinen A, Jämsä T, Kiviranta I, Linnamo V, Komi PV, Sievänen H. Neuromuscular performance and body mass as indices of bone loading in premenopausal and postmenopausal women. Bone 2010;46:964-969.

28. Rantalainen T, Sievänen H, Linnamo V, Hoffrén M, Ishikawa M, Kyröläinen H, Avela J, Selänne H, Komi PV, Heinonen A. Bone rigidity to neuromuscular performance ratio in young and elderly men. Bone 2009;45:956-963.

29. Wundersitz DWT, Gastin PB, Richter C, Robertson SJ, Netto KJ. Validity of a trunkmounted accelerometer to assess peak accelerations during walking, jogging and running. Eur J Sport Sci 2015;15:382-390.

30. Glüer CC, Blake G, Lu Y, Blunt BA, Jergas M, Genant HK. Accurate assessment of precision errors: How to measure the reproducibility of bone densitometry techniques. Osteoporos Int 1995;5:262-270.

31. McGraw KO, Wong SP. Forming inferences about some intraclass correlation coefficients. Psychol Methods 1996;1:30-46.

32. Cicchetti DV. Guidelines, criteria, and rules of thumb for evaluating normed and standardized assessment instruments in psychology. Psychol Assess 1994;6:284.

33. Bland MJ, Altman D. Statistical Methods for Assessing Agreement between Two Methods of Clinical Measurement. The Lancet 1986;327:307-310.

34. Brehm MA, Scholtes VA, Dallmeijer AJ, Twisk JW, Harlaar J. The importance of addressing heteroscedasticity in the reliability analysis of ratio-scaled variables: an example based on walking energy-cost measurements. Dev Med Child Neurol 2012;54:267-273.

35. Bahr MA, Bahr R. Jump frequency may contribute to risk of jumper's knee: a study of interindividual and sex differences in a total of 11943 jumps video recorded during training and matches in young elite volleyball players. Br J Sports Med 2014;48:13221326.

This article is protected by copyright. All rights reserved. 


\section{FIGURES}

Figure 1. Sample of the accelerations recorded in the sensor coordinate system (middle pane), and after transformation into the global coordinate system (bottom pane). The top pane shows the orientation of the sensor axes (indicated by the solid, dashed and dash-dot lines; positive Z-axis points into the page) in the global coordinate system at three different instants indicated by the dashed lines in the two bottom panes. Note the change in sensor orientation from standing still (at $82 \mathrm{~s}$ ) to around the deepest squat (at $82.9 \mathrm{~s}$ ) of the counter movement observable on the solid and dashed sensor axis visualisations.

Figure 2. Scatterplot between jump heights determined based on inertial measurement unit (IMU) recordings. Method ' $\mathrm{a}$ ' flight time was based on acceleration falling below $0.5 \mathrm{~g}$ and raising to over $0.5 \mathrm{~g}$ (IMU jump height refined with acceleration). Method ' $\mathrm{b}$ ' flight time was defined as the epoch from maximal to minimal vertical velocity.

Figure 3. Correspondence between jump-mat and inertial measurement unit (IMU) derived jump heights. IMU-based jump height was determined based on vertical acceleration dropping below $0.5 \mathrm{~g}$ in the vicinity of maximal velocity and rising above $0.5 \mathrm{~g}$ in the vicinity of minimal velocity (method 'a'). Pane A; Bland-Altman plot. Pane B; Scatterplot.

This article is protected by copyright. All rights reserved. 
Figure 4. Correspondence between jump-mat and inertial measurement unit (IMU) derived jump heights. IMU-based jump height was determined based on the flight time defined as the duration from maximal to minimal velocity (method ' $b$ '). Pane A; Bland-Altman plot. Pane B; Scatterplot.

\section{SUPPLEMENTAL DIGITAL CONTENT}

SDC 1. Appendix_Measuring_Jump_Height.pdf; an appendix describing the formulation of the formulae required in calculating jump height based on flight time, take-off velocity, and concentric net impulse.

This article is protected by copyright. All rights reserved. 
Table 1. Descriptive characteristics of the volunteers reported by sex.

\begin{tabular}{llllllllll}
\hline & \multicolumn{3}{c}{ Women $(\mathrm{N}=25)$} & \multicolumn{4}{c}{ Men $(\mathrm{N}=16)$} \\
& Mean & SD & Min & Max & Mean & SD & Min & Max \\
\hline Age [years] & 47 & 21 & 20 & 77 & 36 & 20 & 6 & 75 \\
Height [cm] & 167 & 6 & 156 & 183 & 173 & 16 & 120 & 186 \\
Body Mass [kg] & 64 & 8 & 51 & 85 & 72 & 20 & 20 & 90 \\
\hline
\end{tabular}

This article is protected by copyright. All rights reserved. 

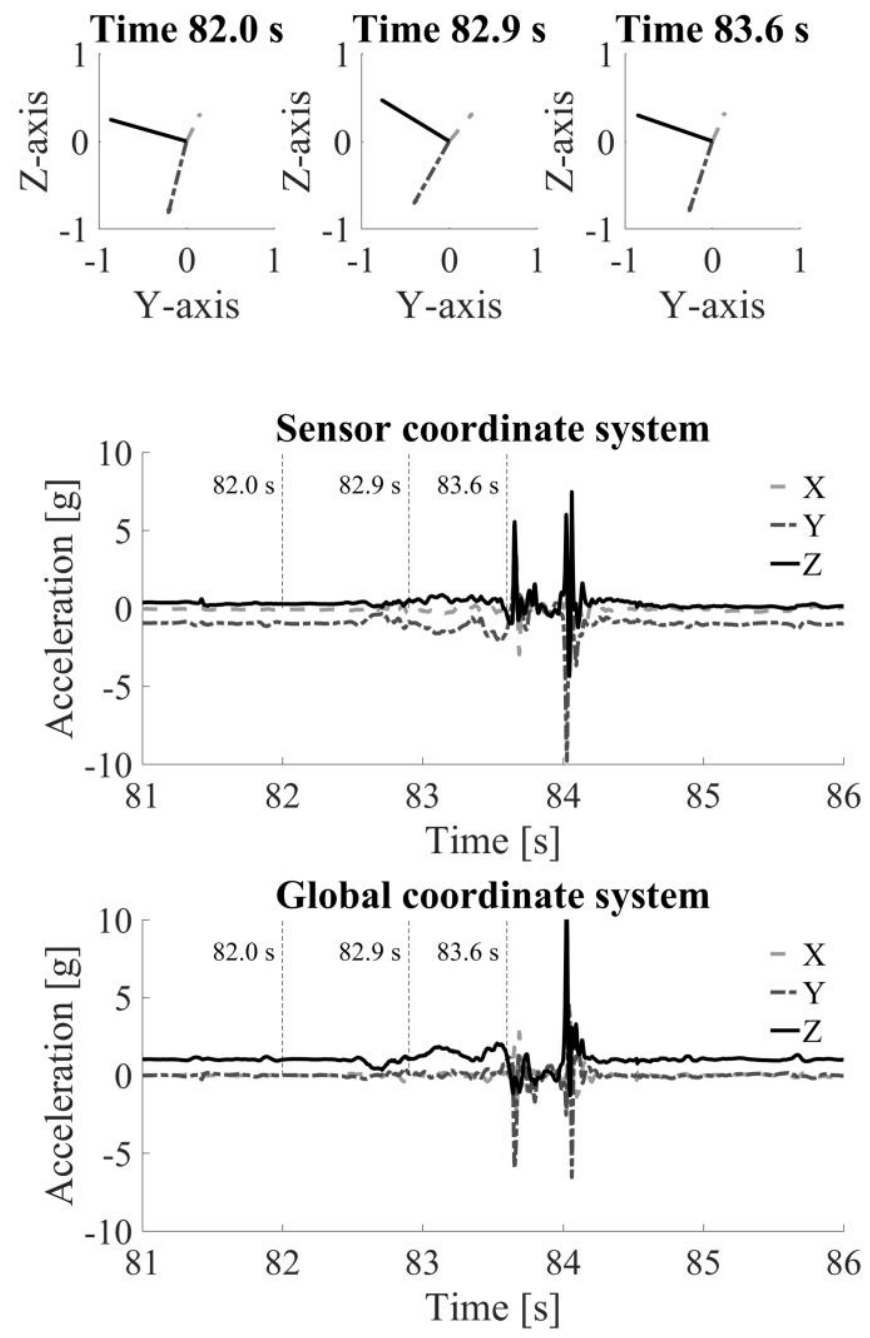

This article is protected by copyright. All rights reserved. 


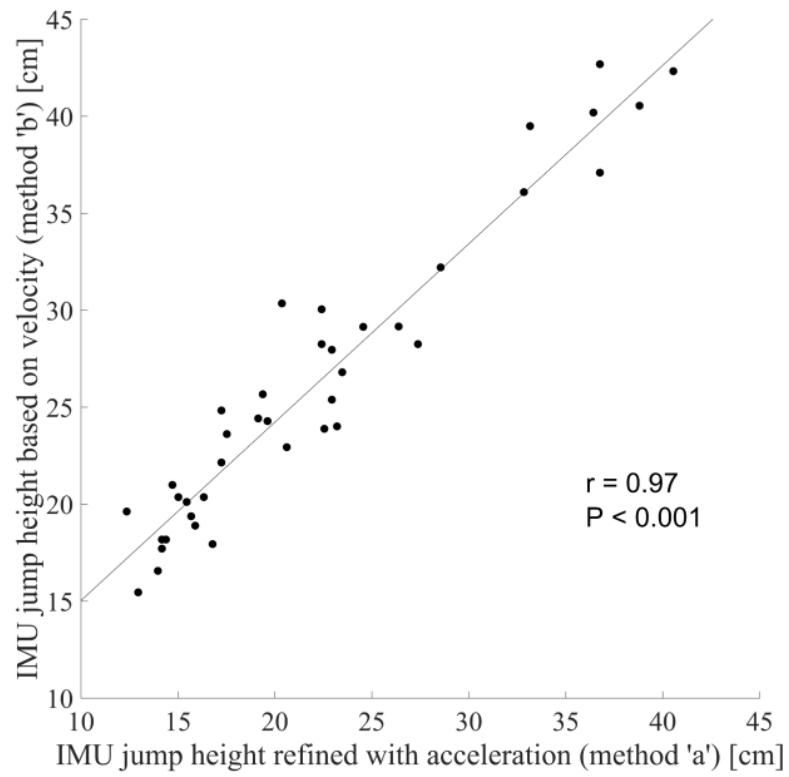

This article is protected by copyright. All rights reserved. 


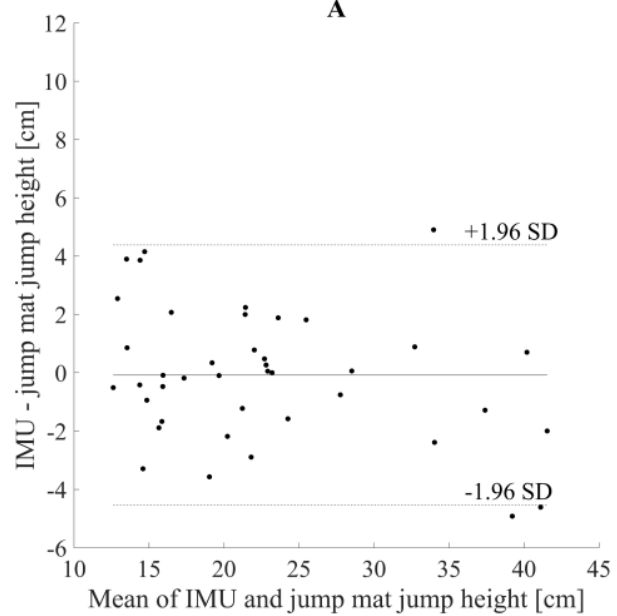

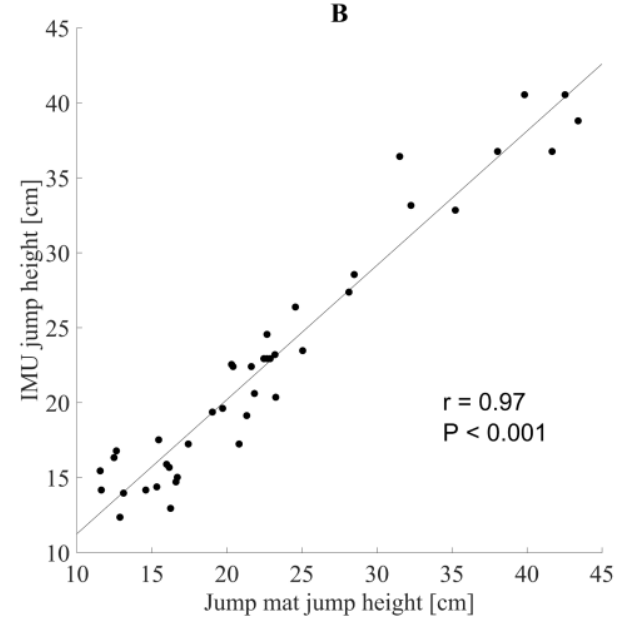

This article is protected by copyright. All rights reserved. 

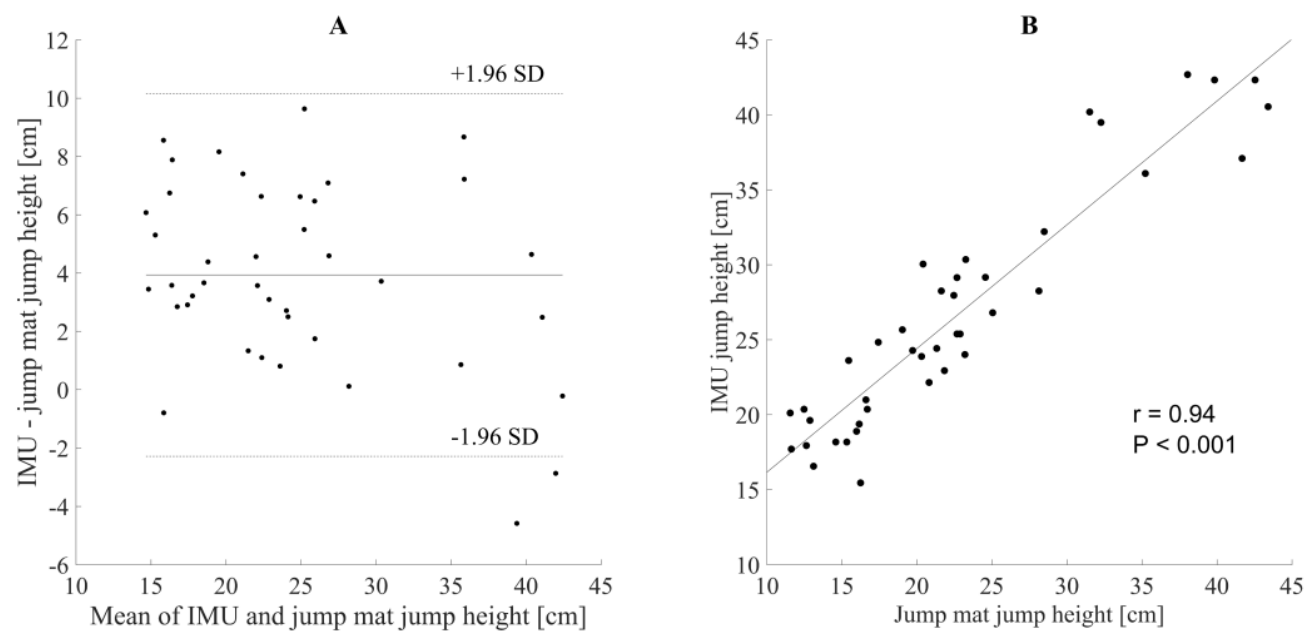

This article is protected by copyright. All rights reserved. 